\title{
The Changing Landscape of Healthcare and Continuing Education
}

BETH FAIMAN, PhD, MSN, APRN-BC, AOCN ${ }^{\circledR}$ FAAN

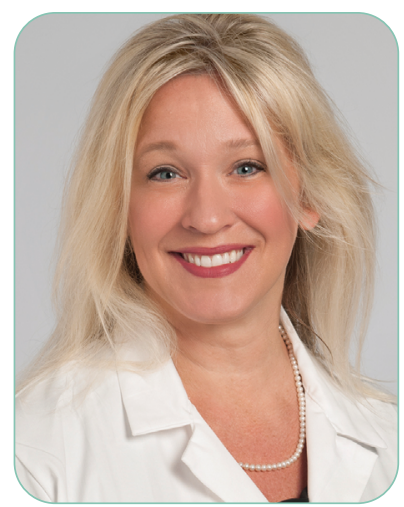

J Adv Pract Oncol 2020;11(7):669-670 https://doi.org/10.6004/jadpro.2020.11.7.1 (c) 2020 Harborside $^{\top M}$ am sure that many of you can agree that summer this year felt different. Few social gatherings took place, if at all. In most cities, youth sports and summer activities such as baseball and swimming were canceled. Despite these disruptions from the norm, the days of summer seemed to fly by as clinical responsibilities grew and evolved due to the coronavirus pandemic. Hard-working advanced practitioners fulfilled critical roles in managing patients both in person and through virtual telehealth services. This was a hectic summer for most, in stark contrast to the summers of the past that were enjoyed by the pool, or through activities with family and friends.

\section{CHANGES TO DELIVERY OF HEALTHCARE FOR PATIENTS AND PROVIDERS}

There is no question that the coronavirus pandemic has interfered with the normal flow of daily clinical practices and changed the way in which patients and providers interact within the health-care system. The delivery of health-care services has changed in response to provider and patient concerns of minimizing risks of coronavirus infection trans- mission, and virtual telehealth services were embraced (Stawicki et al., 2020; The Lancet Haematology, 2020). Many providers were thrust into hospital-based roles and/or virtual telehealth responsibilities that differed from the usual and were often outside of one's comfort zone.

Patients with cancer were also asked to step out of their comfort zone and embrace technology as a method of communicating with providers at a distance instead of via inperson visits (Hwang et al., 2020). This distancing and separation has led some patients to experience anxiety over their health, worry over finances with loss of wages, fear of contracting an illness without clear treatment, and depression (Baddour et al., 2020; O'Connor et al., 2020).

\section{CHANGES IN RECEIVING NEW INFORMATION}

Not only has the delivery of healthcare changed for patients and providers, but interactions between APs in oncology and the receipt of new information within academic communities has changed. Historically, medical and academic conferences would resume in the fall after a summer break. But this year, delayed springtime conferences turned into 
virtual meetings and seemed to continue throughout this summer without pause.

In previous years, I would look forward to inperson meetings-the excitement of traveling to a new city, renewing connections with old friends, and the chance to meet new friends. But I honestly enjoy the flexibility of virtual meetings and the opportunity to gain new knowledge. Once limited by the cost of travel and time needed to be away from work, now, more than ever, I realize and appreciate the benefit of entering a virtual meeting room and the ability to connect with like-minded advanced practitioners or access on-demand content at my convenience. The surge in virtual meetings and conferences has led me to appreciate new perspectives in continuing education.

Academic medical communities have been impacted by the cancellation or change to a virtual platform of most medical and health profession conferences, including JADPRO Live. In order to make participation convenient for attendees who strive to balance clinical and personal responsibilities, JADPRO Live Virtual will take place from October 15 through 23 (with additional content available October 26-November 6). I look forward to an energizing virtual JADPRO Live conference filled with new information, as well as future opportunities to meet some of you in person.

\section{IN THIS ISSUE}

There are a variety of articles in this issue for the advanced practitioner to enjoy. Starting us off in this September/October issue is Dr. Rubin and coauthors revisiting infectious complications following total parenteral nutrition use during hematopoietic stem cell transplantation. Dr. Kim and colleagues outline experiences in utilizing a palliative care screening tool in patients with glioblastoma. The Review article higlights challenges of treating pancreatic ductal adenocarcinoma. Delve into our two Grand Rounds: one on the use of the CDK4/6 inhibitor palbociclib and the other on the phenomenon of pseudoprogression. In our Translating Research Into Practice department, Dr. Kurtin and Ms. Taher share their expertise in clinical trial design and drug approval in oncology. Don't miss their complementary APSHO Educator Module, just launched at APSHO.org. This issue's Practice Matters article by Dr. LeBar and colleagues highlights advanced practitioners and telemedicine as they discuss the transition of an academic commercial chimeric antigen receptor T-cell therapy transplantation program to the outpatient setting. Get a comprehensive review of the new drug alpelisib, a novel therapy for patients with PIK3CA-mutated metastatic breast cancer in our Prescriber's Corner. And finally, test your knowledge on how to evaluate atypical radiculopathy in oncology in our Diagnostic Snapshot.

\section{References}

Baddour, K., Kudrick, L. D., Neopaney, A., Sabik, L. M., Peddada, S. D., Nilsen, M. L.,...Mady, L. J. (2020). Potential impact of the COVID-19 pandemic on financial toxicity in cancer survivors. Head \& Neck, 42(6), 1332-1338. https://doi.org/10.1002/hed.26187

Hwang, E. S., Balch, C. M., Balch, G. C., Feldman, S. M., Golshan, M., Grobmyer, S. R.,...Tanabe, K. K. (2020). Surgical oncologists and the COVID-19 pandemic: Guiding cancer patients effectively through turbulence and change. Annals of Surgical Oncology, 27(8), 2600-2613. https:// doi.org/10.1245/s10434-020-08673-6

O’Connor, D. B., Aggleton, J. P., Chakrabarti, B., Cooper, C. L., Creswell, C., Dunsmuir, S.,...Armitage, C. J. (2020). Research priorities for the COVID-19 pandemic and beyond: A call to action for psychological science. British Journal of Psychology, e12468. https://doi.org/10.1111/ bjop. 12468

Stawicki, S. P., Jeanmonod, R., Miller, A. C., Paladino, L., Gaieski, D. F., Yaffee, A. Q.,...Garg, M. (2020). The 20192020 Novel Coronavirus (Severe Acute Respiratory Syndrome Coronavirus 2) Pandemic: A Joint American College of Academic International Medicine-World Academic Council of Emergency Medicine Multidisciplinary COVID-19 Working Group Consensus Paper. Journal of Global Infectious Diseases, 12(2), 47-93. https://doi. org/10.4103/jgid.jgid_86_20

The Lancet Haematology. (2020). COVID-19 and haematology-oncology services. Lancet Haematology, 7(9), e625. https://doi.org/10.1016/s2352-3026(20)30254-4 